\title{
Treatment and benefit analysis of wastewater from construction of hydropower project
}

\author{
Haitao Ling ${ }^{1}$, Cong $\mathrm{Su}^{2}$, Haotian $\mathrm{Xia}^{2}$, Fei Suo ${ }^{1}$, Mengjie Xiao ${ }^{2}$ and Yue Cheng ${ }^{3}$. \\ ${ }^{1}$ State Grid XinYuan Company Ltd. 100761, Beijing, China \\ ${ }^{2}$ Anhui Jixi Pumped Storage Co., Ltd., 245300, Anhui, China \\ ${ }^{3}$ Anhui Changzhiyuan Environmental Engineering Co., Ltd..230000, Anhui, China
}

\begin{abstract}
In order to treat oil and other pollutants in downstream surface water causing by the construction process of a hydropower project, many methods were used. Besides that, a set of flocculation and precipitation facilities was designed as an emergency device for entire construction site. Good results were achieved in the treatment of construction wastewater, which has obvious economic and environmental benefits and has reference value for similar projects.
\end{abstract}

\section{Introduction}

Hydropower is clean energy with many advantages such as renewable, pollution-free, low operating costs, easy to carry out power peak. It is beneficial to improve the utilization of resources as well as the comprehensive economic and social benefits. In recent years, in order to promote the realization of China's energy transformation goals, China has made various efforts to develop clean energy. Hydropower energy, a green, non-polluting and renewable energy source, has been welcomed by people and has become the key development direction of China's clean energy ${ }^{[1]}$.

Hydropower project generally needs a large scale of investment and a long construction cycle. In the construction process of hydropower project, a large variety of wastewater producing from scattered production points are difficult to collect and treat. It may easily cause pollution of downstream water bodies, and thus endanger health, and may even destroy the ecological balance of the environment ${ }^{[2]}$. In this work, we take a hydropower project as the example, and discuss the treatment methods of wastewater during the construction of the hydropower project. The economic and environmental benefits are also discussed.

\section{Project Profile}

The hydropower project is located in the southern of Anhui, where is rich in water resources and rainwater. According to the routine monitoring data of surface water environmental quality in the lower reaches of the dam during the early stage of construction, it is found that oil and other pollution indicators continue to exceed the standard of water quality. Moreover, the downstream water quality is lugubrious. This phenomenon may be caused by many mechanical equipment and construction personnel involving in the construction process, the dispersion of construction sites as well as the failure to effectively collect running leakage of construction wastewater.

According to the characteristics of construction wastewater, the designers treat and reuse different wastewater in order to solve this problem mentioned above. In order to reduce the pollution discharge causing by the washing of rainwater and wastewater accident discharge, a flocculation and sedimentation equipment was set as an emergency treatment device at the exit of the flood discharge hole of the lower reservoir.

\section{Construction Wastewater Treatment Methods}

\subsection{Sand and gravel washing wastewater}

The main pollutant in the sand and gravel wastewater is SS. The concentration of suspended matter in the wastewater can be as high as tens of thousands of $\mathrm{mg} / \mathrm{L}$ [3]. Due to the restrictions of the construction sites, the use of natural sedimentation for gravel processing sewage treatment is not feasible. Therefore, the comprehensive and dynamic sewage treatment method of "Fine sand recovery + sewage plus drug + tertiary precipitation+ filter press treatment" was adopted. That is to say, gravel processing and sewage treatment are carried out simultaneously. The wastewater treatment process of the gravel processing system is shown in Figure 1. The design scale of the process is $60 \mathrm{~m}^{3} / \mathrm{h}$. The SS concentration of input water is $20000-500000 \mathrm{mg} / \mathrm{L}$, and the SS concentration of output water is $70 \mathrm{mg} / \mathrm{L}$. 


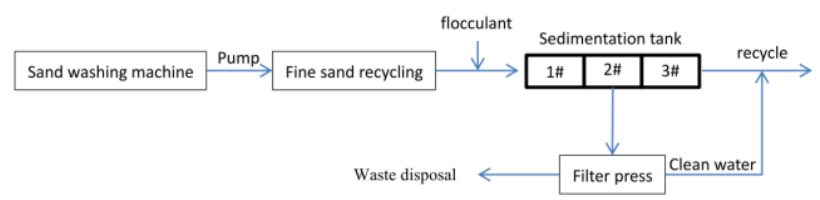

Fig. 1. Flow chart of treatment process of sand and gravel processing system wastewater

As a new type of environmentally friendly equipment, the fine sand recovery unit can significantly reduce the concentration of SS in wastewater to ensure that the subsequent flocculation and sedimentation can operate normally. PAC has obvious water purification effect and fast flocculation and sedimentation rate, which can promote the precipitation effect of SS and shorten the sedimentation time to ensure the effluent quality.

\subsection{Concrete system flushing wastewater}

The wastewater of concrete production system mainly comes from the flushing wastewater of mixing plant and mixing truck, which is produced intermittently. The amount of this wastewater is relatively small, not more than $15 \mathrm{~m}^{3} / \mathrm{d}$. The $\mathrm{pH}$ value of this wastewater is generally larger than 10 . This wastewater contains high SS (ca. $2000 \mathrm{mg} / \mathrm{L}$ ). The concrete system flushing wastewater is treated by "three-stage sedimentation + chemical neutralization". The $\mathrm{pH}$ value is neutralized by adding neutralizing agent (oxalic acid), and then most of the suspended solids can be removed by three-stage sedimentation. After that, the wastewater is used for vehicle, mixing building cleaning and water spraying to suppress dust. After sedimentation, the sediment shall be cleaned regularly and sent to the waste disposal site for stacking after dehydration.

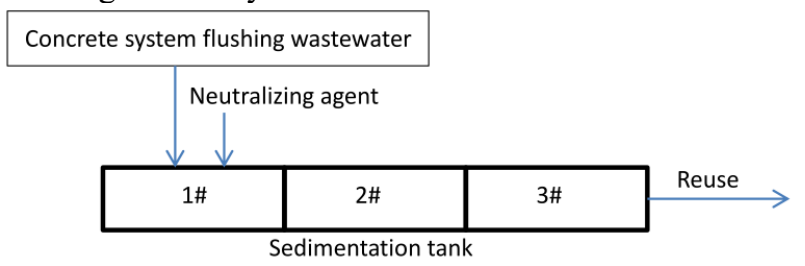

Fig. 2. Flow chart of treatment process of concrete system flushing wastewater

\subsection{Underground chamber wastewater}

The underground chamber wastewater is mainly composed of the construction wastewater of water conveyance tunnel and underground powerhouse cavern group and groundwater inflow. The main pollutants are $\mathrm{pH}$ and SS. The underground chamber wastewater treatment system adopts the process of "sand settling + $\mathrm{pH}$ adjustment + mixing reaction + primary sedimentation + oil scraping + secondary sedimentation". The underground chamber wastewater treatment process is shown in Figure 3.

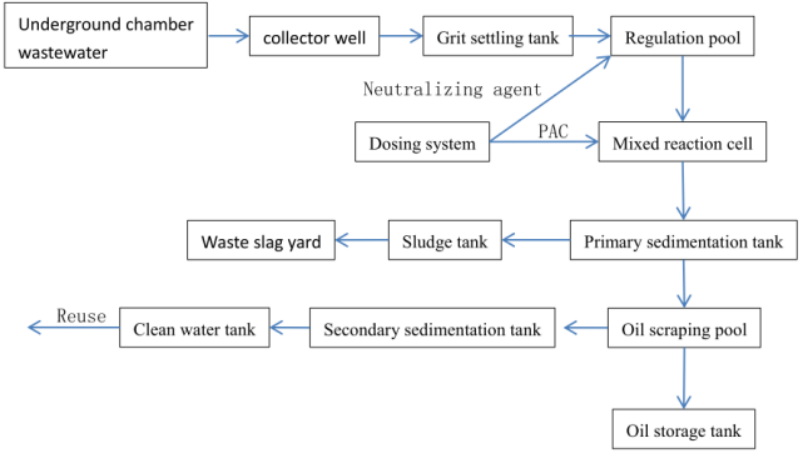

Fig. 3. Flow chart of treatment process of underground chamber wastewater

The design SS concentration in influent water is $10000 \mathrm{mg} / \mathrm{L}$. The design $\mathrm{pH}$ in influent water is $10-13$. The design SS concentration of effluent water is $70 \mathrm{mg} / \mathrm{L}$. The design $\mathrm{pH}$ in effluent water is 6-9. The design scale of the underground chamber wastewater treatment process is $1500 \mathrm{~m}^{3} / \mathrm{d}$. The construction wastewater of the underground chamber is pumped out to the tunnel portal by graded relay via the drainage ditch or water collection well setting in the tunnel. After that, it is transmitted to the wastewater treatment station through the wastewater collection pipeline. After the sedimentation treatment in the grit chamber, the wastewater is first added to the regulating tank for reaction in the mixed reaction tank, and then the clear water is reused after sedimentation treatment in the secondary sedimentation tank.

\subsection{Domestic sewage}

The domestic sewage mainly contains organic pollutants $\left(\mathrm{COD}_{\mathrm{Cr}}, \mathrm{NH}_{3}-\mathrm{N}\right.$, etc.) and $\mathrm{SS}$. There are many construction units involving in the hydropower project. The construction camps are scattered. Each living camp is equipped with a set of integrated domestic sewage treatment facilities and the process used is contact oxidation process. After being treated by integrated sewage treatment facilities, the domestic sewage is pumped out by pumping for irrigation of green plants in the plant. Reuse of domestic sewage after treatment to reduce the impact on downstream surface water.

\subsection{Flocculation and sedimentation in stilling basin}

The construction site of the hydropower project is large. The construction points are scattered. The non-point source pollution will be formed under the scouring of rainwater of various mechanical equipment running, dripping and leaking on the construction points, the mud and slurry water producing during the construction process, the ground washing water, etc. If it is not treated, they will affect the water quality in the downstream. Accidental wastewater discharge may also affect water quality in the downstream. In order to reduce the non-point source pollution of the construction site and accidental wastewater, a set of flocculation and sedimentation device is setting at the outlet of the 
diversion and discharge tunnel of the lower reservoir as an emergency treatment facility. The flocculation and sedimentation device is installed in the stilling basin with a capacity of about $10000 \mathrm{~m}^{3}$. Sewage has enough time to settle in the stilling basin to remove suspended solids.

The flocculation system of the lower stilling basin is mainly composed of water diversion pipeline, tubular static mixer, dosing machine, grid, flocculation equipment reactor, etc. The Technological process is shown in Figure 4. All kinds of sewage on the construction site are collected by confluence via the surrounding pipe network. And then it gets into the water diversion pipeline through the water diversion bell mouth. The rapid mixing of wastewater and flocculant is realized through the tubular static mixer. After the sedimentation of sewage in the coagulation reaction and sedimentation equipment is completed, the upper clear liquid is discharged, and the lower sediment is cleaned regularly through the sludge discharge pipe. The flocculation and sedimentation equipment of the stilling basin can well handle the sewage generated by the accident state or rainy day, and play an insurance role for the downstream surface water.

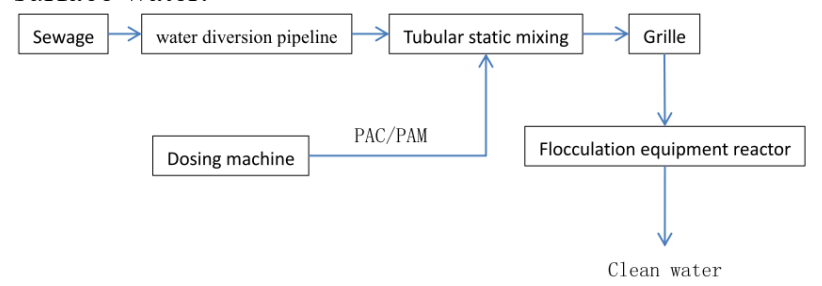

Fig. 4. Flow chart of treatment process of Flocculation and sedimentation in stilling basin

\section{Benefit analysis}

\subsection{Project investment and operation cost}

Take a hydropower project as an example, After adopting the above measures, the quality of downstream surface water has been significantly improved. The investment of wastewater treatment facilities during the construction period is shown in Table 1.

Table 1 Investment in wastewater treatment facilities during construction period of a project

\begin{tabular}{|c|c|}
\hline Source of pollution & $\begin{array}{c}\text { Investment (thousand } \\
\text { yuan) }\end{array}$ \\
\hline $\begin{array}{c}\text { Sand and gravel washing } \\
\text { wastewater }\end{array}$ & $4,200.00$ \\
\hline $\begin{array}{c}\text { Concrete system flushing } \\
\text { wastewater }\end{array}$ & 800.00 \\
\hline $\begin{array}{c}\text { Underground chamber } \\
\text { wastewater }\end{array}$ & $4,100.00$ \\
\hline Domestic sewage & $2,800.00$ \\
\hline Flocculation and \\
sedimentation in stilling basin & 13.100 .00 \\
\hline Total & \\
\hline
\end{tabular}

\subsection{Economic benefit analysis}

The sand and gravel washing wastewater, concrete system washing wastewater and underground chamber wastewater are reused after treatment. If the daily operation of the sand and gravel processing system is 10 $\mathrm{h}$, the daily recycling water volume of a hydropower project is $2115 \mathrm{~m}^{3}$. The cost of river water intake and the resource is about 0.1 yuan $/ \mathrm{m}^{3}$, and the reuse of wastewater can be saved 211.5 yuan/d. If the SS concentration of sand and gravel processing system wastewater is $20000 \mathrm{mg} / \mathrm{L}$, the concrete system washing wastewater is $2000 \mathrm{mg} / \mathrm{L}$, the underground chamber waste water is $10000 \mathrm{mg} / \mathrm{L}$, the amount of suspended solids producing every day is about $27 \mathrm{t}$. The rock type of a project is granite with the density of about $3 \mathrm{t} / \mathrm{m}^{3}$, so the amount of suspended solids is calculated to be about $9 \mathrm{~m}^{3} / \mathrm{d}$. If the generated $\mathrm{SS}$ are discharged into the downstream river without treatment, the downstream river will be silted up and blocked, and the cost of river cleaning is about 80 yuan $/ \mathrm{m}^{3}$.

If the construction period is 8 years and the annual production time is 300 days, the water fee can be saved by 507600 yuan, and the cost of cleaning the SS is about 172800 yuan.

In addition, if the wastewater is discharged directly without treatment, it will seriously affect the downstream agricultural irrigation, resulting in the reduction of the crop and the quality of agricultural products as well as the income of farmers. Therefore, the construction wastewater treatment has obvious economic benefits.

\subsection{Environmental benefit analysis}

During the construction period, the wastewater treatment can reduce the discharge of SS. The average number of constructors in a project is about 2000 , may reaching to 3700 in peak period. The domestic water consumption of construction personnel is about $150 \mathrm{~L} / \mathrm{d}$. The COD concentration of domestic sewage is about $300 \mathrm{mg} / \mathrm{L}$. The $\mathrm{NH}_{3}-\mathrm{N}$ concentration is about $35 \mathrm{mg} / \mathrm{L}$. After treatment, all domestic sewage is reused and irrigated for greening. According to the calculation of 8-year construction period and 300 days of annual construction, COD and $\mathrm{NH}_{3}-\mathrm{N}$ can be reduced by $216 \mathrm{t}$ and $25.2 \mathrm{t}$, respectively. Therefore, in view of pollutant emission reduction effect, the construction wastewater treatment has obvious environmental benefits.

In addition to pollutant reduction and discharge, the construction wastewater treatment also has obvious ecological environment benefits. The discharge of construction wastewater will cause water pollution in the downstream river, affecting the downstream ecosystem and destroying the downstream ecological balance seriously. Guo Lifeng and others ${ }^{[4]}$ constructed a multi index and multi-level eco-environmental benefit evaluation model based on six aspects of river connectivity, water quality, riparian zone, aquatic organisms, river landscape and management status to evaluate the eco-environmental benefit of comprehensive treatment of rural river. According to the evaluation model and the results of routine quality monitoring, the 
construction process has no significant impact on the connectivity, water quality, riparian status, aquatic organisms and river landscape.

\section{Conclusions}

During the construction period of hydropower project, there is a large amount of wastewater producing from scattered production points. It is very important to adopt reasonable construction wastewater treatment facilities for pollution prevention and control during the construction period. Taking a project as an example, this paper introduces various feasible treatment methods and emergency treatment measures for non-point source pollution and accidental wastewater of construction. This paper also analyzes the economic and environmental benefits of construction wastewater treatment of hydropower project that can provide a reference for similar projects.

\section{References}

1. Z. Huang, Rural Economy and Science-technology, 29, 293(2018)

2. Y. Tan, S. Zhang, W. Chen, Water Resources and Power, 37(2019)

3. J. Lang, G. Xie, Proceedings of the Water Pollution Control Engineering Academic Exchange Conference of Sichuan Province (2009)

4. L. Guo, H. Zhang, M. Liu, Z. Wang, R. Zhang, Journal of Ecology and Rural Environment, 34(2018) 